\title{
Nitrogênio da biomassa microbiana em solo de Cerrado com aplicação de fertilizante nitrogenado
}

\author{
Thais Rodrigues Coser(1), Maria Lucrécia Gerosa Ramos(1), Renato Fernando Amabile(2) \\ e Walter Quadros Ribeiro Júnior ${ }^{(3)}$
}

\begin{abstract}
(1)Universidade de Brasília, Fac. de Agronomia e Medicina Veterinária, Caixa Postal 04508, CEP 90 910-970, Brasília, DF. E-mail: thacoser@gmail.com, lucrecia@unb.br (2)Embrapa Cerrados, Caixa Postal 08223, CEP 73301-970 Planaltina, DF. E-mail: amabile@cpac.embrapa.br (3)Embrapa Trigo, Rodovia BR 285, Km 294, CEP 99001-970 Passo Fundo, RS. E-mail: walter@cpac.embrapa.br
\end{abstract}

Resumo - O objetivo deste trabalho foi avaliar o efeito da adubação nitrogenada no nitrogênio da biomassa microbiana do solo $\left(\mathrm{N}_{\text {BMS }}\right.$ ), em diferentes profundidades, em um Latossolo Vermelho-Amarelo cultivado com cevada. O experimento foi instalado em junho de 2004, em área experimental de primeiro ano de plantio direto, anteriormente cultivada com milheto por três anos e posteriormente com soja por duas safras. Foram utilizados os seguintes tratamentos: quatro doses de nitrogênio $\left(30,60,90\right.$ e $\left.120 \mathrm{~kg} \mathrm{ha}^{-1}\right)$ e o controle sem adubação nitrogenada. As amostras de solo foram coletadas em quatro profundidades: $0-5,5-10,10-20$ e $20-30 \mathrm{~cm}$, com três repetições e em três épocas: perfilhamento pleno, floração e logo após a colheita. $O \mathrm{~N}_{\mathrm{BMS}}$ e a razão $\mathrm{N}_{\mathrm{BMS}}: \mathrm{N}_{\text {total }}$ diminuíram com a profundidade. Doses mais elevadas de nitrogênio não aumentaram o $\mathrm{N}_{\mathrm{BMS}}$. $\mathrm{O} \mathrm{N}_{\text {total }}$ não foi alterado nas diferentes doses de nitrogênio, mas diminuiu com a profundidade. Houve correlação negativa entre o $\mathrm{N}_{\text {BMS }}$ e o pH do solo em todas as doses de nitrogênio, com exceção na dose zero. Houve também, correlação positiva entre a razão $\mathrm{N}_{\mathrm{BMS}}: \mathrm{N}_{\text {total }}$ o o $\mathrm{N}_{\mathrm{BMS}}$, porém não entre a razão $\mathrm{N}_{\mathrm{BMS}}: \mathrm{N}_{\text {total }}$ e o $\mathrm{N}_{\text {totall }}$.

Termos para indexação: qualidade do solo, nitrogênio total, Hordeum vulgare.

\section{Microbial biomass nitrogen in cerrado soil with nitrogen fertilizer application}

\begin{abstract}
The objective of this work was to evaluate the effect of different nitrogen doses and soil depths on soil microbial biomass nitrogen $\left(\mathrm{N}_{\mathrm{SMB}}\right)$ in a sandy textured Oxisol, cultivated with barley. The experiment was established in June, 2004, in an area which had been cultivated with millet for three years and subsequently with soya beans for two seasons. The treatments were four doses of nitrogen $\left(30,60,90 \mathrm{e} 120 \mathrm{~kg} \mathrm{ha}^{-1}\right)$ and a control without any dose. Soil samples were collected in four depths: 0-5, 5-10, 10-20 e 20-30 cm, comprising three replicates and three sampling periods: tillering, flowering and right after the harvest. The $\mathrm{N}_{\mathrm{SMB}}$ and $\mathrm{N}_{\mathrm{SMB}}: \mathrm{N}_{\text {total }}$ decreased according to depth. Higher doses of nitrogen did not increase the $\mathrm{N}_{\mathrm{SMB}}$. The $\mathrm{N}_{\text {total }}$ was not altered with the application of nitrogen, but it decreased with depth. There were negative correlations between the $\mathrm{N}_{\mathrm{SMB}}$ and soil $\mathrm{pH}$ for all the doses, except for the treatment without nitrogen. There were also positive correlations between the $\mathrm{N}_{\mathrm{SMB}}: \mathrm{N}_{\text {total }}$ and $\mathrm{N}_{\mathrm{SMB}}$, but not between $\mathrm{N}_{\mathrm{SMB}}: \mathrm{N}_{\text {total }}$ and $\mathrm{N}_{\text {total }}$.
\end{abstract}

Index terms: soil quality, total nitrogen, Hordeum vulgare.

\section{Introdução}

O nitrogênio é o nutriente mais exigido pelas plantas. Este elemento, porém, encontra-se quase totalmente complexado na forma orgânica (98\%), dependendo da biomassa microbiana do solo (BMS), para a sua transformação e, conseqüente, absorção pelas plantas. A BMS representa a menor porcentagem de nitrogênio total (1 a 5\%) do solo, mas é responsável pela reserva lábil e ciclagem de nutrientes, decomposição da matéria orgânica, fluxo de energia (Jenkinson \& Ladd, 1981) e é sensível às mudanças que ocorrem no solo, sendo portanto uma boa indicadora de qualidade do solo (Jackson et al., 2003).

Apenas entre 40 e $60 \%$ do nitrogênio aplicado na forma de fertilizantes é absorvido pelas plantas e $20-50 \%$ é incorporado ao solo como nitrogênio orgânico (Furtini Neto et al., 2001). Porém, pouco se sabe sobre o efeito causado pelas aplicações de fertilizantes nitrogenados na biomassa microbiana do solo, principalmente em ecossistemas tropicais, e em solos sob cerrado. Segundo Jackson et al. 
(2003), perturbações no solo, a curto prazo, afetam negativamente a qualidade do solo quando há aumento de emissões de gases do efeito estufa $\left(\mathrm{NO}, \mathrm{N}_{2} \mathrm{O}\right)$ e perdas de nitrato por lixiviação ou decréscimo na imobilização de nitrogênio pela biomassa microbiana. A imobilização do nitrogênio pela biomassa microbiana do solo aplicado na forma de fertilizante seria uma das maneiras de conservá-lo no sistema solo-planta e retêlo na forma orgânica por determinado período (Jenkinson \& Ladd, 1981).

O crescimento microbiano é limitado, muitas vezes, pela escassez de nutrientes encontrados no solo, mas a adição de fontes de carbono ou nitrogênio ao solo pode aumentar a biomassa e com isso imobilizá-los na sua constituição celular (Graham et al., 2002). Por sua vez, a adição de nitrogênio ao solo apresenta, em sistemas agrícolas e florestais, efeito neutro (Tiquia et al., 2002) de aumento (Silvan et al., 2003) e de diminuição (Cerny et al., 2003) do $\mathrm{N}_{\text {BMS }}$. Tem-se observado aumento da acidez do solo causada pela adição dos fertilizantes nitrogenados e, algumas vezes, associada às mudanças no $\mathrm{N}_{\mathrm{BMS}}$ (Moore et al., 2000). Foram encontradas, também, associações entre o aumento do $\mathrm{N}_{\mathrm{BMS}}$ com a maior fertilidade causada pela adição de nitrogênio e o subseqüente retorno dos restos vegetais ao solo (Silvan et al., 2003). Existem relatos em outros estudos de que a adição de fertilizantes nitrogenados na superfície do solo afeta a BMS e sua atividade, não apenas nas camadas superficiais, mas também nas camadas mais profundas (Zaman et al., 2002).

A disponibilidade de nutrientes e a produtividade de agroecossistemas dependem do tamanho e da atividade da BMS, pois esta representa o carbono e o nitrogênio mais lábil do solo (Jenkinson \& Ladd, 1981). O tempo necessário para que o nitrogênio da biomassa microbiana seja liberado no ambiente é dez vezes maior do que o do material vegetal em decomposição. Assim, a determinação do $\mathrm{N}_{\mathrm{BMS}}$ é de extrema importância para a quantificação da dinâmica do nitrogênio em agroecossistemas, pois controla a disponibilidade e as perdas de nitrogênio inorgânico do solo, principalmente em sistemas em que há fluxo de nitrogênio no solo (Schloter et al., 2003).

O objetivo deste trabalho foi avaliar o efeito da adubação nitrogenada no $\mathrm{N}_{\mathrm{BMS}}$, em diferentes profundidades, em um Latossolo Vermelho-Amarelo cultivado com cevada. Com base na hipótese de que a aplicação de fertilizantes nitrogenados no solo aumenta a BMS até uma dose ótima, que imobiliza o nitrogênio temporariamente, o que evita assim, perdas deste nitrogênio sob formas de nitrato ou óxidos de nitrogênio e aumenta o seu aproveitamento pelas plantas.

\section{Material e Métodos}

O experimento foi instalado em junho de 2004 em uma área de Latossolo Vermelho-Amarelo de textura argilosa da Embrapa Cerrados, no Distrito Federal, que anteriormente havia sido cultivada com milheto, por três anos, e posteriormente com soja, por duas safras. As características químicas do solo na profundidade de 0-20 cm foram: $\mathrm{pH}\left(\mathrm{H}_{2} \mathrm{O}\right), 6,00 ; 0,02 \mathrm{cmol}_{\mathrm{c}} \mathrm{dm}^{-3} \mathrm{de} \mathrm{Al}$; $6,04 \mathrm{cmol}_{\mathrm{c}} \mathrm{dm}^{-3}$ de $\mathrm{Ca}+\mathrm{Mg} ; 20,36 \mathrm{mg} \mathrm{dm}^{-3}$ de $\mathrm{P}$; $146 \mathrm{mg} \mathrm{dm}^{-3}$ de $\mathrm{K}$ e nas camadas entre $0-5,5-10$, $10-20$ e $20-30 \mathrm{~cm}$ foram 20,$18 ; 19,31 ; 18,68$ e $13,73 \mathrm{~g} \mathrm{~kg}^{-1}$ de carbono orgânico e 1,53, 1,55, 1,49 e $1,11 \mathrm{~g} \mathrm{~kg}^{-1}$ de nitrogênio total, respectivamente. A vegetação espontânea foi dessecada com o produto comercial glifosate na dose de $3 \mathrm{~L} \mathrm{ha}^{-1} \mathrm{em}$ pós-emergência, e após total dessecação foi introduzido, pela primeira vez, o sistema de plantio direto naquela área.

A cultivar de cevada utilizada foi a BRS 195, comercialmente utilizada para a indústria cervejeira. Esta cultivar possui ciclo médio de 110 dias para a região do Cerrado, alto perfilhamento e, devido ao seu porte baixo, dificilmente acama com doses altas de nitrogênio aplicadas no plantio e em cobertura. A área foi dividida em 15 parcelas de 1,8x3,5 m com nove linhas de plantio cada e foram utilizadas quatro linhas para fins de produtividade e cinco para a coleta de solo e de plantas para análise. $\mathrm{O}$ experimento compreendeu os seguintes tratamentos: quatro doses de nitrogênio $(30,60,90$ e $120 \mathrm{~kg} \mathrm{~N} \mathrm{ha}^{-1}$ ) e o controle sem adubação nitrogenada. Cada parcela foi adubada com $80 \mathrm{~kg} \mathrm{ha}^{-1}$ de P e $60 \mathrm{~kg} \mathrm{ha}^{-1} \mathrm{de} \mathrm{K}$, e utilizou-se como fonte de nitrogênio o sulfato de amônio. $\mathrm{O}$ nitrogênio, fósforo e potássio foram aplicados a lanço para não descaracterizar o sistema de plantio direto. A aplicação do nitrogênio foi parcelada, $30 \mathrm{~kg} \mathrm{ha}^{-1}$ aplicado logo após o plantio e o restante foi adicionado em cobertura no início do estádio de perfilhamento da planta. As coletas de solo foram realizadas em três épocas: perfilhamento pleno, floração e logo após a colheita, que corresponde a 3, 24 e 76 dias após a aplicação de nitrogênio em cobertura, respectivamente. As amostras de solo foram coletadas em quatro profundidades: $0-5,5-10,10-20$ e $20-30 \mathrm{~cm}$, e em cada profundidade foram coletadas cinco 
subamostras nas entrelinhas, o que se considerou uma amostra composta. As amostras foram mantidas em caixas de isopor, resfriadas durante o transporte até o laboratório e preservadas em câmara fria a $4^{\circ} \mathrm{C}$.

Cada tratamento foi composto por três parcelas, que representaram as repetições. O delineamento experimental foi em blocos ao acaso, em parcelas subdivididas; as doses de nitrogênio foram as parcelas, e as profundidades, as subparcelas.

O N $\mathrm{N}_{\mathrm{BMS}}$ foi calculado pelo método de fumigação e extração (Brookes et al., 1985; Vance et al., 1987; Jenkinson et al., 2004). As amostras foram peneiradas em malha de $8 \mathrm{~mm}$ de abertura, retirando-se fragmentos de raízes e restos vegetais. Antes do processo de fumigação, os teores de umidade das amostras foram corrigidos para $80 \%$ da capacidade máxima de retenção de água no solo. As amostras foram divididas em subamostras (triplicatas) de $20 \mathrm{~g}$ de solo e incubadas por sete dias. Parte das amostras foi submetida ao processo de fumigação, seguida de extração, e a outra parte, apenas ao processo de extração. As amostras foram fumigadas com clorofórmio isento de etanol por 24 horas e, posteriormente, retiradas e extraídas, com as amostras não fumigadas. As amostras foram extraídas com $\mathrm{K}_{2} \mathrm{SO}_{4}$ 0,5M com pH ajustado entre 6,5 a 6,8 em agitador contínuo a uma velocidade de $150 \mathrm{rpm}$ por 40 min e depois filtradas. A seguir, foram retiradas alíquotas de $20 \mathrm{~mL}$ e transferidas para tubos de vidro com $1 \mathrm{~g}$ de mistura catalítica $\left(\mathrm{K}_{2} \mathrm{SO}_{4}: \mathrm{CuSO}_{4}\right.$ :selênio em pó, na relação 1:0,1:0,01) e $3 \mathrm{~mL}$ de $\mathrm{H}_{2} \mathrm{SO}_{4}$ concentrado. Em seguida, realizou-se a digestão a $80^{\circ} \mathrm{C}$ por 12 horas, $150^{\circ} \mathrm{C}$ por 1 hora e 30 min e $300^{\circ} \mathrm{C}$ durante 3 horas.

A destilação foi realizada com $20 \mathrm{~mL}$ da solução de $400 \mathrm{~g} \mathrm{NaOH} \mathrm{L}^{-1}$ de água destilada. Preparou-se uma mistura com $15 \mathrm{~mL}$ de verde de bromocresol e $6 \mathrm{~mL}$ de vermelho de metila a $0,1 \%$ em meio alcoólico, $20 \mathrm{~g}$ de $\mathrm{H}_{3} \mathrm{BO}_{3}$ e três gotas de $\mathrm{NaOH} 0,1 \mathrm{~N}$, completada com
$1 \mathrm{~L}$ de água destilada. Utilizaram-se $10 \mathrm{~mL}$ dessa mistura para coletar o destilado em erlenmeyer de $50 \mathrm{~mL}$. Procedeu-se à titulação com $\mathrm{H}_{2} \mathrm{SO}_{4} \quad 0,0025 \mathrm{~N}$. As amostras tituladas sem a adição de substrato serviram como branco. O nitrogênio extraído pelas amostras fumigadas e não fumigadas foi calculado pela sua diferença com o branco, e posteriormente por regra de três, supondo-se que 1 meq de $\mathrm{H}_{2} \mathrm{SO}_{4}$ equivaleria a $0,0025 \mathrm{e}$ 1 meq de $\mathrm{NH}_{4}^{+}$a 0,005 .

O nitrogênio microbiano foi calculado pela fórmula: $\mathrm{N}$ da biomassa $=\left(\mathrm{N}_{\mathrm{F}}-\mathrm{N}_{\mathrm{NF}}\right) \mathrm{K}_{\mathrm{EN}^{-1}}$, em que $\mathrm{N}_{\mathrm{F}}$ e $\mathrm{N}_{\mathrm{NF}}$ são as quantidades totais de nitrogênio mineral liberado dos solos fumigados e não fumigados, respectivamente. $O \mathrm{~K}_{\mathrm{EN}}(0,54)$ é uma constante que representa a proporção do nitrogênio da biomassa microbiana que é mineralizada (Wardle, 1994). Para cada amostra coletada, foram realizadas três repetições analíticas em laboratório e para o cálculo do $\mathrm{N}_{\mathrm{BMS}}$ foi calculada a média destas três repetições.

O nitrogênio total do solo $\left(\mathrm{N}_{\text {total }}\right)$ e das folhas foi estimado pelo método Kjeldahl, de acordo com Bremner \& Mulvaney (1982). O carbono orgânico ( $\mathrm{C}_{\mathrm{ORG}}$ ) foi calculado pelo método da oxidação por via úmida (Walkley \& Black, 1934).

Os dados foram analisados com utilização do programa SANEST (Zonta et al., 1984), e as comparações das médias foram realizadas pelo teste de Tukey, a 5\% de probabilidade.

\section{Resultados e Discussão}

Houve interação significativa entre as doses de nitrogênio e as profundidades no $\mathrm{N}_{\mathrm{BMS}}$ logo após a colheita da cultura (Tabela 1). Foi observado aumento no $\mathrm{N}_{\text {BMS }}$ apenas para a dose de $60 \mathrm{~kg} \mathrm{ha}^{-1}$ na camada de $0-5 \mathrm{~cm}$. Nas outras camadas do perfil do solo, não foi constatado efeito da adição de nitrogênio ao solo e o $\mathrm{N}_{\mathrm{BMS}}$ diminuiu com o

Tabela 1. Nitrogênio da biomassa microbiana $\left(\mathrm{mg} \mathrm{kg}^{-1}\right)$ em solo cultivado com cevada e submetido a diferentes doses de nitrogênio, em quatro profundidades, logo depois da colheita ${ }^{(1)}$.

\begin{tabular}{ccccc}
\hline Profundidade $(\mathrm{cm})$ & \multicolumn{3}{c}{ Doses de N $\left(\mathrm{kg} \mathrm{ha}^{-1}\right)$} \\
\cline { 2 - 5 } & \multicolumn{1}{c}{0} & 30 & 60 & 90 \\
\hline $0-5$ & $28,67 \mathrm{bA}$ & $33,60 \mathrm{abA}$ & $38,39 \mathrm{aA}$ & $29,64 \mathrm{bA}$ \\
$5-10$ & $24,66 \mathrm{aA}$ & $26,61 \mathrm{aB}$ & $20,03 \mathrm{aB}$ & $24,85 \mathrm{aB}$ \\
$10-20$ & $17,39 \mathrm{aB}$ & $18,29 \mathrm{aC}$ & $19,25 \mathrm{aB}$ & $18,05 \mathrm{aC}$ \\
$20-30$ & $16,26 \mathrm{aB}$ & $11,41 \mathrm{aD}$ & $14,34 \mathrm{aC}$ & $26,36 \mathrm{aB}$ \\
$21,13 \mathrm{aC}$ & $11,36 \mathrm{aC}$ \\
\hline
\end{tabular}

(1)Médias seguidas pela mesma letra, minúscula nas linhas (comparação entre doses) e maiúscula nas colunas (comparação entre as profundidades), não diferem entre si pelo teste de Tukey, a 5\% de probabilidade. 
aumento da profundidade, corroborando o estudo realizado por Perez et al. (2005).

Houve interação significativa entre as doses de nitrogênio e as profundidades nos dados da relação $\mathrm{C}_{\mathrm{ORG}}: \mathrm{N}_{\text {total }}$ do solo apenas no perfilhamento pleno (Tabela 2). A relação $\mathrm{C}_{\mathrm{ORG}}: \mathrm{N}_{\text {total }}$ do solo variou entre 13,78 , para a dose de $60 \mathrm{~kg} \mathrm{ha}^{-1}$ na camada de $0-5 \mathrm{~cm}$, e 16,29, para a dose de $120 \mathrm{~kg} \mathrm{ha}^{-1}$ na camada de $10-20 \mathrm{~cm}$. No perfilhamento, não foi observado nenhum efeito na relação $\mathrm{C}_{\mathrm{ORG}}: \mathrm{N}_{\text {total }}$ com a aplicação de nitrogênio nas camadas entre 0 e $30 \mathrm{~cm}$, com exceção da dose de $120 \mathrm{~kg} \mathrm{ha}^{-1}$ que foi estatisticamente superior à dose de $60 \mathrm{~kg} \mathrm{ha}^{-1}$ na camada de $10-20 \mathrm{~cm}$, e a dose de $30 \mathrm{~kg} \mathrm{ha}^{-1}$ que apresentou relação $\mathrm{C}_{\mathrm{ORG}}: \mathrm{N}_{\text {total }}$ maior que a dose de $120 \mathrm{~kg} \mathrm{ha}^{-1}$ na camada de $20-30 \mathrm{~cm}$. Na época da floração, houve diferença somente entre as profundidades e obteve-se, na camada de $20-30 \mathrm{~cm}$, o maior valor da relação $\mathrm{C}_{\text {ORG }}: \mathrm{N}_{\text {total, }}$, porém, foi estatisticamente superior apenas à camada de $0-5 \mathrm{~cm}$. Como não ocorreu diferença entre as doses de nitrogênio nas camadas entre 0 a $10 \mathrm{~cm}$, considerou-se que, independentemente da relação $\mathrm{C}_{\mathrm{ORG}}: \mathrm{N}_{\text {total }}$ da palhada na superfície, a aplicação de doses mais elevadas de nitrogênio não promoveu a mineralização de nitrogênio, tampouco, o imobilizou na biomassa microbiana do solo (Tabela 1). Blankenau et al. (2000) consideraram o $\mathrm{N}_{\mathrm{BMS}}$ um indicador fraco da imobilização de nitrogênio adicionado ao solo na forma de fertilizantes, pois apenas 2,9 a 23,8\% do nitrogênio perdido do sistema solo-planta foi imobilizado na biomassa microbiana para a cultura do trigo.

Hatch et al. (2000) e Vargas et al. (2005) observaram aumentos no $\mathrm{N}_{\mathrm{BMS}}$, apenas a longo prazo, em solo sob pastagem e plantio direto, respectivamente. Esses autores argumentaram que isso se deveu ao efeito da maior produção de biomassa vegetal e do conseqüente aumento de carbono orgânico no solo. O mesmo foi observado no trabalho de Silvan et al. (2003); a imobilização de $\mathrm{N}$ na BMS ocorreu apenas um ano depois do início do experimento. Segundo Zaman et al. (2002) e Blankenau et al. (2000), adições de resíduos orgânicos, concomitantemente com fertilizantes nitrogenados, aumentaram o $\mathrm{N}_{\mathrm{BMS}}$ comparado ao tratamento sem a adição de resíduos orgânicos. Porém, no primeiro ano de plantio direto, neste trabalho, foi observado que a aplicação de doses elevadas de nitrogênio (90 e $\left.120 \mathrm{~kg} \mathrm{ha}^{-1}\right)$ proporcionou a mesma imobilização de nitrogênio na biomassa microbiana que o tratamento sem a aplicação de nitrogênio, na camada de $0-5 \mathrm{~cm}$ e, nas outras camadas, não houve diferença significativa para o $\mathrm{N}_{\mathrm{BMS}}$ entre as diferentes doses de nitrogênio (Tabela 1).

Anderson \& Domsch (1980) observaram que os microrganismos diferem muito mais no seu teor de nitrogênio do que no de carbono, dependendo do seu estágio de crescimento. Portanto, pequenas mudanças na estrutura da biomassa microbiana podem resultar em grandes mudanças no $\mathrm{N}_{\mathrm{BMS}}$. Porém, a adição de substratos ao solo a curto prazo, provavelmente afeta uma pequena parte da BMS que está ativa, ao passo que a resposta a longo prazo acaba por modificar a sua composição por seleção (Lovell \& Jarvis, 1998).

Não foram encontradas diferenças significativas entre as doses de nitrogênio no perfilhamento, na floração e logo após a colheita, para o $\mathrm{N}_{\text {total }}$, porém, este diminuiu com a profundidade, assim como no trabalho de Peacock et al. (2001). Igualmente, Hatch et al. (2000) não encontraram efeitos a curto prazo no $\mathrm{N}_{\text {total }}$. Aumentos consideráveis de $\mathrm{N}_{\text {total }}$ foram constatados no experimento de Graham et al. (2002), que realizaram uma avaliação a longo prazo e verificaram maior acúmulo de matéria orgânica no tratamento com aplicação de nitrogênio. Varvel (1994), em um estudo de oito anos, observou em experimento de rotações de culturas e aplicações de nitrogênio ao solo, que ocorreram mudanças mínimas no $\mathrm{N}_{\text {total }}$ com adição de nitrogênio ao solo, nos sistemas de monocultura de soja e de rotação milhosoja. Mudanças em outros sistemas de culturas ocorreram, basicamente, nas camadas de $0-7,5 \mathrm{~cm}$ onde havia concentração alta de matéria orgânica. A quantidade de resíduo orgânico que retorna ao solo com a utilização

Tabela 2. $\mathrm{C}_{\mathrm{ORG}}: \mathrm{N}_{\text {total }}$ em solo cultivado com cevada e submetido a diferentes doses de nitrogênio, em quatro profundidades, 30 dias depois do plantio(1).

\begin{tabular}{cllcc}
\hline Profundidade $(\mathrm{cm})$ & \multicolumn{4}{c}{ Doses de $N\left(\mathrm{~kg} \mathrm{ha}^{-1}\right)$} \\
\cline { 2 - 5 } & 0 & 30 & 60 & 90 \\
\hline $0-5$ & $14,58 \mathrm{aAB}$ & $13,99 \mathrm{aA}$ & $13,78 \mathrm{aA}$ & $14,55 \mathrm{aA}$ \\
$5-10$ & $14,10 \mathrm{aB}$ & $14,49 \mathrm{aA}$ & $14,06 \mathrm{aA}$ & $14,41 \mathrm{aA}$ \\
$10-20$ & $14,33 \mathrm{abAB}$ & $14,48 \mathrm{abA}$ & $13,61 \mathrm{bA}$ & $14,59 \mathrm{aAB}$ \\
$20-30$ & $16,31 \mathrm{aA}$ & $14,25 \mathrm{abA}$ & $14,92 \mathrm{abA}$ & $15,77 \mathrm{abA}$ \\
\hline
\end{tabular}

(1)Médias seguidas pela mesma letra, minúscula nas linhas (comparação entre doses) e maiúscula nas colunas (comparação entre as profundidades), não diferem entre si pelo teste de Tukey, a $5 \%$ de probabilidade. 
da soja em monocultura é muito baixa, $3,0 \mathrm{Mg} \mathrm{ha}^{-1}$ por ano (Varvel, 1994). Havlin (1990) observou que quanto mais freqüente o uso da soja em sistemas de rotação, menor a concentração de $\mathrm{N}_{\text {total }}$ no solo. Joergensen \& Scheu (1999) encontraram aumento no $\mathrm{N}_{\text {total }}$ apenas na camada com maior acúmulo de matéria orgânica. Depreende-se que o nitrogênio mineral adicionado por fertilizantes não é incorporado na fração do nitrogênio total do solo, ao contrário do nitrogênio orgânico, que advém da decomposição dos resíduos orgânicos.

Antes do plantio da cultura da cevada, a soja havia sido cultivada, na área, por dois anos consecutivos, logo, sua contribuição para o $\mathrm{N}_{\text {total }}$ foi mínima devido à sua rápida decomposição no solo. Os resultados da análise de nitrogênio na folha-bandeira da cultura da cevada mostraram que as doses de $90 \mathrm{~kg} \mathrm{ha}^{-1}\left(36,17 \mathrm{~g} \mathrm{~kg}^{-1}\right) \mathrm{e}$ $120 \mathrm{~kg} \mathrm{ha}^{-1}\left(35,90 \mathrm{~g} \mathrm{~kg}^{-1}\right)$ acumularam, significativamente, mais nitrogênio que os tratamentos sem aplicação de nitrogênio $\left(25,25 \mathrm{~g} \mathrm{~kg}^{-1}\right)$, com $30\left(23,66 \mathrm{~g} \mathrm{~kg}^{-1}\right)$ e com $60 \mathrm{~kg} \mathrm{ha}^{-1}\left(29,99 \mathrm{~g} \mathrm{~kg}^{-1}\right)$. À medida que se aumentava a dose de nitrogênio no solo, aumentava, também, o teor de nitrogênio na planta. Portanto, boa parte do nitrogênio mineral aplicado ao solo foi assimilada pela planta e não incorporada na fração do $\mathrm{N}_{\text {total, }}$ o que explica a ausência de efeito da deposição do nitrogênio no solo. A maior concentração de nitrogênio na planta é, em muitos casos, relacionada à maior biomassa vegetal. Nas parcelas cujas doses de nitrogênio foram maiores, a biomassa vegetal cobriu bastante o solo, levando à maior retenção de umidade e possivelmente maior deslocamento descendente do nitrato para camadas mais profundas do solo. A umidade do solo, no estudo desenvolvido por Gama-Rodrigues et al. (2005), explicou $87 \%$ da variação dos teores de $\mathrm{N}_{\text {total }}$ e nitrogênio nítrico no solo.

A relação $\mathrm{N}_{\mathrm{BMS}}: \mathrm{N}_{\text {total }}$ oferece uma estimativa da quantidade de nutriente, disponibilidade de substrato e a dinâmica da matéria orgânica no solo, pois, quanto maior esta relação, melhor será a qualidade da matéria orgânica (Sparling, 1992). Houve interação entre a razão percentual $\mathrm{N}_{\mathrm{BMS}}: \mathrm{N}_{\text {total }}$ nas três épocas de avaliação (Tabelas 3, 4 e 5). A relação $\mathrm{N}_{\mathrm{BMS}}: \mathrm{N}_{\text {total }}$ variou de 1,05 a 3,61\%. Estes valores estão de acordo com os valores de Fauci \& Dick (1994), que variaram de 1 a 7\%.

Tabela 3. $\mathrm{N}_{\mathrm{BMS}}: \mathrm{N}_{\text {total }}(\%)$ em solo cultivado com cevada e submetido a diferentes doses de nitrogênio, em quatro profundidades, no perfilhamento ${ }^{(1)}$.

\begin{tabular}{|c|c|c|c|c|c|}
\hline \multirow[t]{2}{*}{ Profundidade $(\mathrm{cm})$} & \multicolumn{5}{|c|}{ Doses de $\mathrm{N}\left(\mathrm{kg} \mathrm{ha}^{-1}\right)$} \\
\hline & 0 & 30 & 60 & 90 & 120 \\
\hline $0-5$ & $2,33 b c A$ & $2,62 \mathrm{bA}$ & $1,97 \mathrm{cA}$ & $3,61 \mathrm{aA}$ & $2,53 \mathrm{bcA}$ \\
\hline $5-10$ & $2,27 \mathrm{aAB}$ & $2,33 \mathrm{aAB}$ & $1,83 \mathrm{aA}$ & $2,04 \mathrm{aB}$ & $1,81 \mathrm{aB}$ \\
\hline $10-20$ & $1,55 \mathrm{aC}$ & $1,89 \mathrm{aBC}$ & $2,05 \mathrm{aA}$ & $2,04 \mathrm{aB}$ & $1,81 \mathrm{aB}$ \\
\hline $20-30$ & $1,71 \mathrm{abBC}$ & $1,55 \mathrm{abcC}$ & $1,89 \mathrm{aA}$ & $1,23 \mathrm{bcC}$ & $1,05 \mathrm{cC}$ \\
\hline
\end{tabular}

(1)Médias seguidas pela mesma letra, minúscula nas linhas (comparação entre doses) e maiúscula nas colunas (comparação entre as profundidades), não diferem entre si pelo teste de Tukey, a 5\% de probabilidade.

Tabela 4. $\mathrm{N}_{\mathrm{BMS}}: \mathrm{N}_{\text {total }}(\%)$ em solo cultivado com cevada e submetido a diferentes doses de nitrogênio, em quatro profundidades, na floração(1).

\begin{tabular}{clllll}
\hline Profundidade $(\mathrm{cm})$ & \multicolumn{5}{c}{ Doses de N $\left(\mathrm{kg} \mathrm{ha}^{-1}\right)$} \\
\cline { 2 - 6 } & 0 & 30 & 60 & 90 & 120 \\
\hline $0-5$ & $2,66 \mathrm{aA}$ & $2,36 \mathrm{abA}$ & $1,96 \mathrm{aAB}$ & $2,48 \mathrm{aA}$ & $2,33 \mathrm{abA}$ \\
$5-10$ & $2,18 \mathrm{aB}$ & $2,28 \mathrm{aA}$ & $2,08 \mathrm{aA}$ & $2,24 \mathrm{aAB}$ & $2,05 \mathrm{aAB}$ \\
$10-20$ & $2,30 \mathrm{aB}$ & $1,95 \mathrm{abA}$ & $1,61 \mathrm{bBC}$ & $1,96 \mathrm{abB}$ & $1,72 \mathrm{abB}$ \\
$20-30$ & $2,23 \mathrm{aAB}$ & $1,44 \mathrm{bB}$ & $1,43 \mathrm{bC}$ & $1,11 \mathrm{bC}$ & $1,10 \mathrm{bC}$ \\
\hline
\end{tabular}

${ }^{(1)}$ Médias seguidas pela mesma letra, minúscula nas linhas (comparação entre doses) e maiúscula nas colunas (comparação entre as profundidades), não diferem entre si pelo teste de Tukey, a 5\% de probabilidade.

Tabela 5. $\mathrm{N}_{\mathrm{BMS}}: \mathrm{N}_{\text {total }}(\%)$ em solo cultivado com cevada e submetido a diferentes doses de nitrogênio, em quatro profundidades, logo depois da colheita ${ }^{(1)}$.

\begin{tabular}{cccccc}
\hline Profundidade $(\mathrm{cm})$ & \multicolumn{5}{c}{ Doses de $\mathrm{N}\left(\mathrm{kg} \mathrm{ha}^{-1}\right)$} \\
\cline { 2 - 6 } & 0 & 30 & 60 & 90 & 120 \\
\hline $0-5$ & $2,26 \mathrm{bA}$ & $2,51 \mathrm{abA}$ & $2,90 \mathrm{aA}$ & $2,36 \mathrm{abA}$ & $2,44 \mathrm{abA}$ \\
$5-10$ & $2,03 \mathrm{aA}$ & $2,12 \mathrm{aB}$ & $1,61 \mathrm{aB}$ & $2,08 \mathrm{aA}$ & $2,11 \mathrm{aAB}$ \\
$10-20$ & $1,44 \mathrm{aB}$ & $1,52 \mathrm{aC}$ & $1,63 \mathrm{aB}$ & $1,55 \mathrm{aB}$ & $1,77 \mathrm{aB}$ \\
$20-30$ & $1,98 \mathrm{aA}$ & $1,30 \mathrm{bC}$ & $1,54 \mathrm{abB}$ & $1,54 \mathrm{abB}$ & $1,35 \mathrm{bC}$ \\
\hline
\end{tabular}

${ }^{(1)}$ Médias seguidas pela mesma letra, minúscula nas linhas (comparação entre doses) e maiúscula nas colunas (comparação entre as profundidades), não diferem entre si pelo teste de Tukey, a $5 \%$ de probabilidade. 
A relação $\mathrm{N}_{\mathrm{BMS}}: \mathrm{N}_{\text {total }}$ também aumentou com a adição de $90 \mathrm{~kg} \mathrm{ha}^{-1}$ de nitrogênio na camada de $0-5 \mathrm{~cm}$, no perfilhamento (Tabela 3 ), que apresentou o maior valor para a relação $\mathrm{N}_{\mathrm{BMS}}: \mathrm{N}_{\text {total }}(3,61 \%)$.

No perfilhamento (Tabela 3), não foi observado nenhum efeito na relação $\mathrm{N}_{\mathrm{BMS}}: \mathrm{N}_{\text {total }}$ com a aplicação de nitrogênio nas camadas entre $5-30 \mathrm{~cm}$, com exceção da dose de $120 \mathrm{~kg} \mathrm{ha}^{-1}$, que proporcionou valor mais baixo que o tratamento sem aplicação de nitrogênio na camada de 20-30 cm. Moore et al. (2000) também não observaram diferenças significativas entre o tratamento sem e com a aplicação de nitrogênio para a relação $\mathrm{N}_{\mathrm{BMS}}: \mathrm{N}_{\text {total }}$, mas sim entre os tratamentos de monocultivo e de rotação.

$\mathrm{Na}$ floração, nas camadas entre 0 e $10 \mathrm{~cm}$, não foi observado nenhum efeito na relação $\mathrm{N}_{\mathrm{BMS}}: \mathrm{N}_{\text {total }}$ com a adição de nitrogênio ao solo (Tabela 4). Na camada de $10-20 \mathrm{~cm}$, a dose de $60 \mathrm{~kg} \mathrm{ha}^{-1}$ diminuiu a relação $\mathrm{N}_{\mathrm{BMS}}: \mathrm{N}_{\text {total }}$, enquanto as outras não diferiram desta e nem do tratamento sem aplicação de nitrogênio. Já na camada de 20-30 cm, todos os tratamentos com aplicação de nitrogênio ao solo, diminuíram a relação $\mathrm{N}_{\mathrm{BMS}}: \mathrm{N}_{\text {total }}$ em relação ao controle.

Logo após a colheita, não foram observados efeitos da adição de nitrogênio nas camadas entre 0 e $20 \mathrm{~cm}$, com exceção da dose de $60 \mathrm{~kg} \mathrm{ha}^{-1}$, na camada de $0-5 \mathrm{~cm}$, que apresentou valor mais alto que a dose sem nitrogênio (Tabela 5). Na camada de 20-30 cm, as doses de 30 e $120 \mathrm{~kg} \mathrm{ha}^{-1}$ diminuíram a relação $\mathrm{N}_{\mathrm{BMS}}: \mathrm{N}_{\text {total }}$, ao passo que as outras doses não diferenciaram destas e do tratamento sem nitrogênio. Em geral, a relação $\mathrm{N}_{\mathrm{BMS}}: \mathrm{N}_{\text {total }}$ diminuiu à medida que a profundidade aumentou.

Os parâmetros $\mathrm{N}_{\text {total }}$ e $\mathrm{N}_{\mathrm{BMS}}$ correlacionaram-se positivamente (Tabela 6). Porém, no estudo de McCarty et al. (1995), ao se extrapolar o $\mathrm{N}_{\mathrm{BMS}}$ e o nitrogênio ativo do solo para zero, observou-se que o $\mathrm{N}_{\text {total }}$ terá valores diferentes de zero. Isto é uma indicação de que o reservatório de $\mathrm{N}_{\mathrm{BMS}}$ e o nitrogênio ativo do solo são frações distintas das do $\mathrm{N}_{\text {total }}$. Segundo Moore et al. (2000), existe uma reserva inerte de nitrogênio no solo, que obviamente não teve influência positiva nos valores de $\mathrm{N}_{\text {BMS }}$. Observa-se também, pelas correlações entre os parâmetros, que a relação entre $\mathrm{N}_{\mathrm{BMS}}: \mathrm{N}_{\text {total }}$ e $\mathrm{N}_{\text {total }}$ foi não-significativa nos tratamentos sem aplicação de nitrogênio, com $120 \mathrm{~kg} \mathrm{ha}^{-1} \mathrm{e} 60 \mathrm{~kg} \mathrm{ha}^{-1}$, logo a relação variou basicamente em função do $\mathrm{N}_{\mathrm{BMS}}$.

$\mathrm{O} \mathrm{pH}$ correlacionou-se negativamente com todas as variáveis estudadas (Tabela 6), porém, apenas para os tratamentos com aplicação de nitrogênio ao solo. $\mathrm{O}$ pH do solo para a dose de $60 \mathrm{~kg} \mathrm{ha}^{-1}$ não se correlacionou com a relação $\mathrm{N}_{\mathrm{BMS}}: \mathrm{N}_{\text {total. }}$ A correlação entre $\mathrm{pH}$ e $\mathrm{N}_{\mathrm{BMS}}$ foi baixa, em comparação às outras doses de nitrogênio. A baixa BMS encontrada por Witter et al. (1993), em solos com adições de sulfato de amônio, associada à diminuição do $\mathrm{pH}$, em razão de fatores de estresse, que exigem maior energia para a manutenção dos microrganismos, não foi observada. Observou-se relação inversamente proporcional entre o $\mathrm{N}_{\mathrm{BMS}}$ e o $\mathrm{pH}$ do solo e, portanto, a diminuição do $\mathrm{pH}$ com adições crescentes de nitrogênio ao solo pode ter sido um dos fatores responsáveis para aumento do $\mathrm{N}_{\mathrm{BMS}}$, encontrado em alguns tratamentos.

Foi observada correlação negativa entre o $\mathrm{pH}$ e o $\mathrm{N}_{\text {BMS }}$ para os tratamentos com aplicação de nitrogênio (Tabela 6). Observa-se que, quando o pH do solo aumenta em 1 unidade, o $\mathrm{N}_{\mathrm{BMS}}$ diminui quase 40 unidades, indicando possivelmente que a acidificação do solo pode ter favorecido a população de fungos, que tem participação maior na biomassa microbiana do solo (Figuras 1 e 2).

Na camada de $0-5 \mathrm{~cm}$, no perfilhamento, foram observados aumentos da relação $\mathrm{N}_{\mathrm{BMS}}: \mathrm{N}_{\text {total }}$ com a adição da dose de $90 \mathrm{~kg} \mathrm{ha}^{-1}$ (Tabela 3). Portanto, a aplicação de $90 \mathrm{~kg} \mathrm{ha}^{-1}$ ao solo, na camada de $0-5 \mathrm{~cm}$, proporcionou melhoria na qualidade da matéria orgânica e

Tabela 6. Coeficiente de correlação linear de Pearson entre nitrogênio da biomassa microbiana do solo $\left(\mathrm{N}_{\mathrm{BMS}}\right)$, nitrogênio total $\left(\mathrm{N}_{\text {total }}\right)$, relação $\mathrm{N}_{\mathrm{BMS}}$ e $\mathrm{N}_{\text {total }}$ e $\mathrm{pH}$ nas diferentes doses de nitrogênio, considerando todas as épocas e profundidades.

\begin{tabular}{|c|c|c|c|c|}
\hline Variável & $\mathrm{N}_{\mathrm{BMS}}$ & $\mathrm{N}_{\text {total }}$ & $\mathrm{N}_{\mathrm{BMS}}: \mathrm{N}_{\text {total }}$ & $\mathrm{pH}$ \\
\hline \multicolumn{5}{|c|}{$0 \mathrm{~kg} \mathrm{ha}^{-1}$} \\
\hline $\mathrm{N}_{\mathrm{BMS}}$ & - & $0,555^{* *}$ & $0,721 * *$ & $0,272^{\text {ns }}$ \\
\hline $\mathrm{N}_{\text {total }}$ & $0,555^{* *}$ & - & $-0,170^{\mathrm{ns}}$ & $-0,079^{\mathrm{ns}}$ \\
\hline $\mathrm{N}_{\mathrm{BMS}}: \mathrm{N}_{\text {total }}$ & $0,721 * *$ & $-0,170^{\mathrm{ns}}$ & - & $0,345^{*}$ \\
\hline \multicolumn{5}{|c|}{$30 \mathrm{~kg} \mathrm{ha}^{-1}$} \\
\hline $\mathrm{N}_{\mathrm{BMS}}$ & - & $0,691 * *$ & $0,907 * *$ & $-0,577 * *$ \\
\hline $\mathrm{N}_{\text {total }}$ & $0,691 * *$ & - & $0,337 *$ & $-0,425 * *$ \\
\hline $\mathrm{N}_{\text {BMS }}: \mathrm{N}_{\text {total }}$ & $0,907 * *$ & $0,337 *$ & - & $-0,511 * *$ \\
\hline \multicolumn{5}{|c|}{$60 \mathrm{~kg} \mathrm{ha}^{-1}$} \\
\hline $\mathrm{N}_{\mathrm{BMS}}$ & - & $0,640 * *$ & $0,901 * *$ & $-0,338^{*}$ \\
\hline $\mathrm{N}_{\text {total }}$ & $0,640 * *$ & - & $0,253^{\mathrm{ns}}$ & $-0,460 * *$ \\
\hline $\mathrm{N}_{\mathrm{BMS}}: \mathrm{N}_{\text {total }}$ & $0,901 * *$ & $0,253^{\mathrm{ns}}$ & - & $-0,184^{\mathrm{ns}}$ \\
\hline \multicolumn{5}{|c|}{$90 \mathrm{~kg} \mathrm{ha}^{-1}$} \\
\hline $\mathrm{N}_{\mathrm{BMS}}$ & - & $0,626 * *$ & $0,950 * *$ & $-0,708 * *$ \\
\hline $\mathrm{N}_{\text {total }}$ & $0,626 * *$ & - & $0,368 *$ & $-0,639 * *$ \\
\hline $\mathrm{N}_{\text {BMS }}: \mathrm{N}_{\text {total }}$ & $0,950 * *$ & $0,368^{*}$ & - & $-0,595 * *$ \\
\hline \multicolumn{5}{|c|}{$120 \mathrm{~kg} \mathrm{ha}^{-1}$} \\
\hline $\mathrm{N}_{\mathrm{BMS}}$ & - & $0,659 * *$ & $0,890 * *$ & $-0,725 * *$ \\
\hline $\mathrm{N}_{\text {total }}$ & $0,659 * *$ & - & $0,256^{\mathrm{ns}}$ & $-0,542 * *$ \\
\hline $\mathrm{N}_{\mathrm{BMS}}: \mathrm{N}_{\text {total }}$ & $0,890 * *$ & $0,256^{\mathrm{ns}}$ & - & $-0,626 * *$ \\
\hline
\end{tabular}

ns Não-significativo. * e **Significativo a 5 e $1 \%$ de probabilidade pelo teste de Tukey. 
maior aproveitamento desta pelos microrganismos. O trabalho desenvolvido por Vance \& Chapin III (2001) mostrou que, quando o nitrogênio foi aplicado em solo, cuja matéria orgânica era de boa qualidade (relação $\mathrm{N}_{\mathrm{BMS}}: \mathrm{N}_{\text {total }}$ alta), houve maior imobilização do nitrogênio aplicado na biomassa microbiana e também menor respiração microbiana e mineralização do que em um solo com matéria orgânica de baixa qualidade (relação $\mathrm{N}_{\text {BMS }}: \mathrm{N}_{\text {total }}$ baixa).

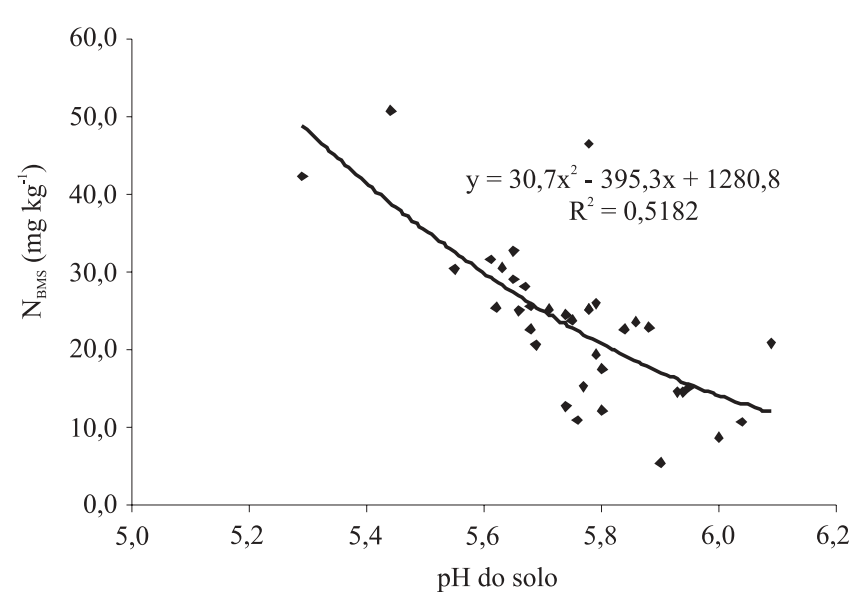

Figura 1. Efeito do $\mathrm{pH}$ no nitrogênio da biomassa microbiana do solo $\left(\mathrm{N}_{\mathrm{BMS}}\right)$, na dose de $90 \mathrm{~kg} \mathrm{ha}^{-1}$ de nitrogênio.

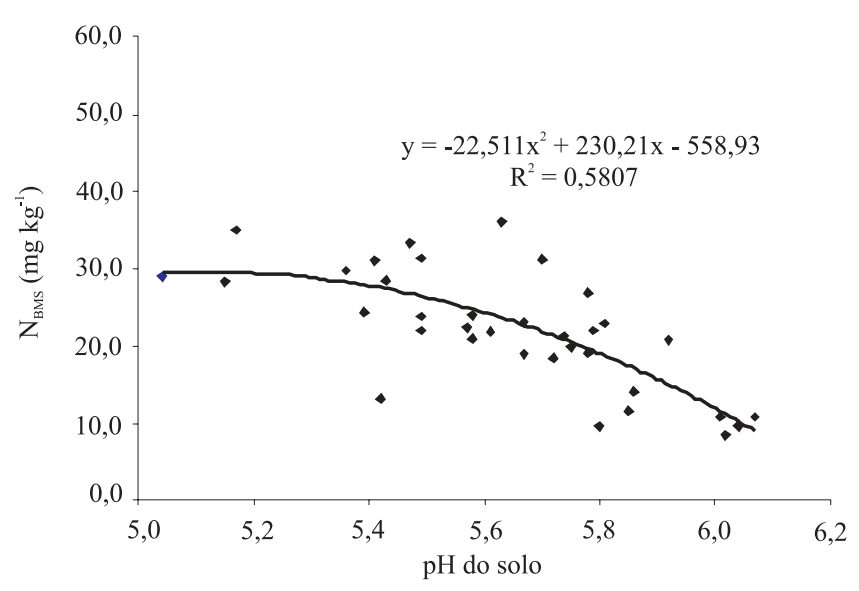

Figura 2. Efeito do $\mathrm{pH}$ no nitrogênio da biomassa microbiana do solo $\left(\mathrm{N}_{\mathrm{BMS}}\right)$, na dose de $120 \mathrm{~kg} \mathrm{ha}^{-1}$ de nitrogênio.

\section{Conclusões}

1. O nitrogênio da biomassa microbiana do solo $\left(\mathrm{N}_{\mathrm{BMS}}\right)$ e a razão $\mathrm{N}_{\text {BMS }}: \mathrm{N}_{\text {total }}$ diminuem com a profundidade do solo.

2. Doses mais elevadas de nitrogênio (acima de $90 \mathrm{~kg} \mathrm{ha}^{-1}$ ) não aumentam o $\mathrm{N}_{\mathrm{BMS}}$.

3. $\mathrm{O} \mathrm{N}_{\text {total }}$ não se altera com a adubação nitrogenada.

4. $\mathrm{O} \mathrm{N}_{\mathrm{BMS}}$ e o pH do solo correlacionam-se negativamente em todas as doses de nitrogênio, com exceção na dose zero.

5. A razão $\mathrm{N}_{\mathrm{BMS}}: \mathrm{N}_{\text {total }}$ e o $\mathrm{N}_{\mathrm{BMS}}$ correlacionam-se positivamente, porém não com o $\mathrm{N}_{\text {total }}$.

\section{Referências}

ANDERSON, J.P.E.; DOMSCH, K.H. Quantities of plant nutrients in the microbial biomass of selected soils. Soil Science, v.130, p.211216, 1980.

BLANKENAU, K.; OLFS, H.-W.; KUHLMANN, H. Effect of microbial nitrogen immobilization during the growth period on the availability of nitrogen fertilizer for winter cereals. Biology and Fertility of Soils, v.32, p.157-165, 2000.

BREMNER, J.M.; MULVANEY, C.S. Nitrogen total. In: PAGE, A.L.; MILLER, R.H.; KEENEY, D.R. (Ed.). Methods of soil analysis: chemical and microbiological properties. $2^{\text {nd }}$ ed. Madison: American Society of Agronomy, 1982. v.2, p.595-624. (Agronomy monograph, 9).

BROOKES, P.C.; LANDMAN, A.; PRUDEN, G.; JENKINSON, D.S. Chloroform fumigation and the release of soil nitrogen: a rapid direct extraction method to measure microbial biomass nitrogen in soil. Soil Biology and Biochemistry, v.17, p.837-842, 1985.

ERNÝ, J.; BALÍK, J.; PAVLÍKOVÁ, D.; ZITKOVÁ, M.; SÝKORA, $\mathrm{K}$. The influence of organic and mineral nitrogen fertilizers on microbial biomass nitrogen and extractable organic nitrogen in longterm experiments with maize. Plant, Soil and Environment, v.49, p.560-564, 2003.

FAUCI, M.F.; DICK, R.P. Soil microbial dynamics: short-term and long-term effects of inorganic and organic nitrogen. Soil Science Society of America Journal, v.58, p.801-806, 1994.

FURTINI NETO, A.E.; VALE, F.R.; RESENDE, A.V.; GUILHERME, L.R.G.; GUEDES, G.A.A. Fertilidade do solo. Lavras: Ufla/Faepe, 2001. 252p.

GAMA-RODRIGUES, E.F. da; BARROS, N.F. de; GAMARODRIGUES, A.C. da; SANTOS, G. de A. Nitrogênio, carbono e atividade da biomassa microbiana do solo em plantações de eucalipto. Revista Brasileira de Ciência do Solo, v.29, p.893-901, 2005.

GRAHAM, M.H.; HAYNES, R.J.; MEYER, J.H. Soil organic matter content and quality: effects of fertilizer applications, burning and trash retention on a long-term sugarcane experiment in South Africa. Soil Biology and Biochemistry, v.34, p.93-102, 2002.

HATCH, D.J.; LOVELL, R.D.; ANTIL, R.S.; JARVIS, S.C.; OWEN, P.M. Nitrogen mineralization and microbial activity in permanent 
pastures amended with nitrogen fertilizer or dung. Biology and Fertility of Soils, v.30, p.288-293, 2000.

HAVLIN, J.L.; KISSEL, D.E.; MADDUX, L.D.; CLAASSEN, M.M.; LONG, J.H. Crop rotation and tillage effects on soil organic carbon and nitrogen. Soil Science Society of America Journal, v.54, p.448-452, 1990.

JACKSON, L.E.; CALDERON, F.J.; STEENWERTH, K.L.; SCOW, K.M.; ROLSTON, D.E. Responses of soil microbial processes and community structure to tillage events and implications for soil quality. Geoderma, v.114, p.305-317, 2003.

JENKINSON, D.S.; BROOKES, P.C.; POWLSON, D.S. Measuring soil microbial biomass. Soil Biology and Biochemistry, v.36, p.57, 2004

JENKINSON, D.S.; LADD, J.N. Microbial biomass in soil: measurement and turnover. In: PAUL, E.A.; LADD, J.N. Soil biochemistry. New York: M. Dekker, 1981. v.5, p.415-471.

JOERGENSEN, R.G.; SCHEU, S. Response of soil microorganisms to the addition of carbon, nitrogen and phosphorus in a forest Rendzina. Soil Biology and Biochemistry, v.31, p.859-866, 1999. LOVELL, R.D.; JARVIS, S.C. Soil microbial biomass and activity in soil from different grassland management treatments stored under controlled conditions. Soil Biology and Biochemistry, v.30, p.2077-2085, 1998.

McCARTY, G.W.; MEISINGER, J.J.; JENNISKENS, F.M.M. Relationships between total-N, biomass-N and active-N in soil under different tillage and $\mathrm{N}$ fertilizer treatments. Soil Biology and Biochemistry, v.27, p.1245-1250, 1995.

MOORE, J.M.; KLOSE, S.; TABATABAI, M.A. Soil microbial biomass carbon and nitrogen as affected by cropping systems. Biology and Fertility of Soils, v.31, p.200-210, 2000.

PEACOCK, A.D.; MULLEN, M.D.; RINGELBERG, D.B.; TYLER, D.D.; HEDRICK, D.B.; GALE, P.M.; WHITE, D.C. Soil microbial community responses to dairy manure or ammonium nitrate applications. Soil Biology and Biochemistry, v.33, p.1011-1019, 2001.

PEREZ, K.S.S.; RAMOS, M.L.G.; McMANUS, C. Nitrogênio da biomassa microbiana em solo cultivado com soja, sob diferentes sistemas de manejo, nos Cerrados. Pesquisa Agropecuária Brasileira, v.40, p.137-144, 2005.

SCHLOTER, M.; DILLY, O.; MUNCH, J.C. Indicators for evaluating soil quality. Agriculture, Ecosystems and Environment, v.98, p.255-262, 2003.

SILVAN, N.; VASANDER, H.; KARSISTO, M.; LAINE, J. Microbial immobilisation of added nitrogen and phosphorus in constructed wetland buffer. Applied Soil Ecology, v.24, p.143-149, 2003.

SPARLING, G.P. Ratio of microbial biomass carbon to soil organic carbon as a sensitive indicator of changes in soil organic matter. Australian Journal of Soil Research, v.30, p.195-207, 1992.

TIQUIA, S.M.; LLOYD, J.; HERMS, D.A.; HOITINK, H.A.J.; MICHEL JUNIOR, F.C. Effects of mulching and fertilization on soil nutrients, microbial activity and rhizosphere bacterial community structure determined by analysis of TRFLPs of PCR-amplified 16S rRNA genes. Applied Soil Ecology, v.21, p.31-48, 2002.

VANCE, E.D.; BROOKES, P.C.; JENKINSON, D.S. An extraction method for measuring soil microbial biomass C. Soil Biology and Biochemistry, v.19, p.703-707, 1987.

VANCE, E.D.; CHAPIN III, F.S. Substrate limitations to microbial activity in taiga forest floors. Soil Biology and Biochemistry, v.33, p.173-188, 2001.

VARGAS, L.K.; SELBACH, P.A.; SÁ, E.L.S. de. Imobilização de nitrogênio em solo cultivado com milho em sucessão à aveia preta nos sistemas plantio direto e convencional. Ciência Rural, v.35, p.76-83, 2005.

VARVEL, G.E. Rotation and nitrogen fertilization effects on changes in soil carbon and nitrogen. Agronomy Journal, v.86, p.319-325, 1994.

WALKLEY, A.; BLACK, I.A. An examination of the Degtjareff method for determining soil organic matter and a proposed modification of the chronic tritation method. Soil Science, v.37, p.29-38, 1934.

WARDLE, D.A. Metodologia para a quantificação da biomassa microbiana do solo. In: HUNGRIA, M.; ARAÚJO, R.S. Manual de métodos empregados em estudos de microbiologia agrícola. Brasília: Embrapa-SPI; Goiânia: Embrapa-CNPAF; Londrina: Embrapa-CNPSo, 1994. 542p. (Embrapa-CNPAF. Documentos, 46).

WITTER, E.; MÅRTENSSON, A.M.; GARCIA, F.V. Size of the soil microbial biomass in a long-term field experiment as affected by different $\mathrm{N}$-fertilizers and organic manures. Soil Biology and Biochemistry, v.25, p.659-669, 1993.

ZAMAN, M.; CAMERON, K.C.; DI, H.J.; INUBUSHI, K. Changes in mineral $\mathrm{N}$, microbial biomass and enzyme activities in different soil depths after surface applications of dairy shed effluent and chemical fertilizer. Nutrient Cycling in Agroecosystems, v.63, p.275-290, 2002.

ZONTA, E.P.; MACHADO, A.D.; SILVEIRA JUNIOR, P. SANEST: sistema de análise estatística para microcomputadores. Pelotas: UFPel, 1984. 75p.

Recebido em 11 de maio de 2006 e aprovado em 6 de dezembro de 2006 